\title{
ENVIRONMENTAL DYNAMICS AND ENGINEERED SYSTEMS FOR THE DEGRADATION OF TRICHLOROETHYLENE: A CRITICAL REVIEW
}

\author{
AMIN M.T. ${ }^{1, *}$ \\ HAMID S. ${ }^{1}$ \\ ALAZBA A.A. ${ }^{1}$ \\ AMIN M.N. ${ }^{2}$ \\ ISLAM M. ${ }^{3}$ \\ MANZOOR U. ${ }^{1}$
}

\author{
${ }^{1}$ Alamoudi Water Research Chair, King Saud University \\ P.O. Box 2460, Riyadh 11451, Kingdom of Saudi Arabia \\ ${ }^{2}$ Department of Civil \& Environmental Engineering \\ College of Engineering, King Faisal University \\ P.O. Box 380, Al-Hofuf, Al-Ahsa 31982, Kingdom of Saudi Arabia \\ ${ }^{3}$ College of Engineering, King Saud University \\ P.O. Box 800, Riyadh 11421, Kingdom of Saudi Arabia
}

Received: $16 / 01 / 2014$

Accepted: 21/02/2014

Available online: 10/03/2014
* to whom all correspondence should be addressed: e-mail: mtamin@ksu.edu.sa

\begin{abstract}
Trichloroethylene (TCE) is found in all mediums of environment in varying concentrations. Over the past 25 years, many engineered systems have been devised for its complete and sustainable degradation. This study reviews the environmental factors that influence the TCE pollution in environment and its biological mineralization via engineered systems. Although at some polluted sites natural attenuation of TCE has been found to occur but generally the natural process is very slow. The use of nanoparticles and composites provides a comparatively novel approach for the treatment of TCE contaminated waters. Biological engineered systems have been found to degrade TCE on much faster rates and higher concentrations. To identify the appropriate microorganisms in any engineered system that can effectively provide a low-cost treatment option for TCE degradation is the pressing need at the moment. Adding a second distinct organic phase to the aqueous medium for degrading fast and high concentration of TCE is recommended. The organic phase, which do not mix with the aqueous phase and can be easily separated, discharged, and reuse, should be selected based on its insolubility, volatility, non-biodegradability by the selected microorganism and the cost of the overall engineered system. Biodegradation offers the potential of cost effective treatment of TCE, however, that engineered systems should effectively use the biodegradative metabolism that nature has evolved.
\end{abstract}

Keywords: Biodegradation, engineered systems, microorganisms, nanoparticles, second phase, TCE

\section{Introduction}

From its invention, Trichloroethylene (TCE) has been produced on large scales and has been used for many purposes e.g. textile processing, refrigeration, lubricants and adhesives, for the production of vinyl chloride (VC), pharmaceuticals, and insecticides (Schettler et al., 1999; US EPA, 2011). Mainly used as a universal degreasing and cleaning agent (Bakke et al., 2007), TCE has vast trails of pollutions in all environmental mediums i.e. soil, air and water, from as low as $0.001 \mu \mathrm{g} \mathrm{I}^{-1}$ to as high as $100000 \mu \mathrm{g} \mathrm{I}^{-1}$ (CEPA, 1993).

Although toxic effects were suspected from TCE exposure, it was not regulated until late 1980's. For example in US and Canada, environmental regulations were imposed in 1989 and 1995, respectively. Recently, strong relationship has been found between TCE exposure and cancer. More reliable results were published to relate kidney cancer due to TCE exposure (Scott et al., 2011; Karami et al., 2012; Chiu 
et al., 2013). Several other health effects were also reported e. g. toxicity to the central nervous system, kidney, liver, immune system, male reproductive system, and the developing embryo/fetus through any type of exposure to TCE has been also found (Chiu et al., 2013). Other than its own health drawbacks, it is a precursor to $V C$ which is a strong and known carcinogen. Other daughter product like dichloroethylene (DCE) is also double bonded between two carbons like TCE and VC (Fig.1). Hence it is recommended that TCE contamination site should also be checked for VC contamination.

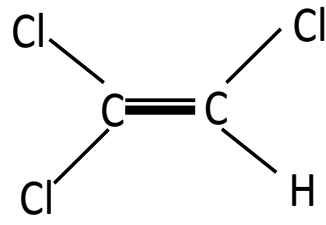

(a)<smiles>ClC=CCl</smiles>

(b)<smiles>C=CCl</smiles>

(c)

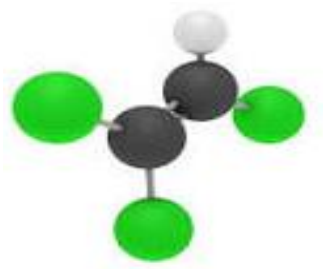

(d)

Figure 1. Molecular structure of (a) TCE; (b) 1,1-DCE; (c) VC, and (d) TCE structural model (From Wikipedia, the free encyclopedia)

TCE has unique properties with respect to contact with environment. It is heavier than water and also volatile. A spill of TCE proceeds in all dimensions. Due to heavier nature, it movies downward and adheres to soil particles, as well as volatilizes to air. Unlike many other common pollutants, it is not readily available for microbial degradation. It is stable in the sunlight and does not decompose through ordinary sunlight photo catalysis. Although it is heavier than water, yet some content of TCE is soluble in water. Major part of it is absorbed by the blood on inhalation through or ingestion through water. Bioaccumulation in plants tissue is not found. Table 1 describes some of its physical and chemical properties.

Table 1. Physical and chemical properties of TCE (Russel et al., 1992; Chiao et al., 1994; Jacoby et al., 1998)

\begin{tabular}{ccc}
\hline Parameter & Unit & Value \\
\hline Molecular weight & $\mathrm{g} \mathrm{mol}^{-1}$ & 131.39 \\
\hline Melting point & ${ }^{\circ} \mathrm{C}$ & -86.5 \\
\hline Boiling point & ${ }^{\circ} \mathrm{C}$ & 87.3 \\
\hline Vapor pressure & $\mathrm{Pa}$ & 9700 \\
\hline Diffusion coefficient in pure air & $\mathrm{m}^{2}$ day $^{-1}$ & 0.68 \\
\hline Diffusion coefficient in pure water & $\mathrm{m}^{2}$ day $^{-1}$ & 0.00009 \\
\hline Water solubility & $\mathrm{gl}^{-1}$ & 1 \\
\hline
\end{tabular}

Due to recalcitrant nature, TCE remains in all media in most of the cases. However, when it is absorbed by animal and humans, biological processes occurring in human body makes it hazardous causing many adverse health effects as stated earlier. Hence it is reported as priority pollutant by many agencies like Environmental Protection Agency (EPA) and Agency for Toxic Substances and Disease and Registry (ATSDR) (ATSDR, 2009). Most importantly, it is urged that ground water plumes of TCE must be remediated to avoid hazards to masses using groundwater as drinking and household use.

\section{Strategies of TCE Remediation}

Since TCE hazards were comprehended, efforts to remediate TCE started. Several types of techniques have been reported to date for TCE remediation. With respect to nature, physical, chemical and biological processes have been employed. For example, pump and treat, soil flushing, in-well aeration, 
air stripping, pump and treat, permeable reactive barrier, electro kinetics (EK), oxidation and reduction with reagents, thermal treatment and biodegradation etc. have been documented with pros and cons of each technique (Huang et al., 2013).

A number of techniques like biological processes (Dong et al., 2009)., in situ chemical oxidation and reduction (Al-Abed and Fang, 2007; Waldemer et al., 2007; Katsanou et al., 2008; Cope and Benson, 2009; Tsai et al., 2009; Phillips et al., 2010), and electrochemical transformation processes (Petersen et al., 2007; Mishra et al., 2008; Carter and Farrell, 2009; Lohner et al., 2011; Mao et al., 2011, 2012) have been used for TCE removal from groundwater. The application of nanoparticles for TCE degradation is increasing rapidly. The biological degradation of TCE was studied by using nanoparticles which remain reactive in soil and water for up to several weeks (Zhang, 2003; Macé et al., 2006; Zhang and Elliott, 2006). The application of nanoparticles has not only reduced the operating cost but also the time of exposure to the contaminated sites (Karn et al., 2009).

The application of bimetallic nanoparticles like Ni/Fe and $\mathrm{Pd} / \mathrm{Fe}$ serves a useful method for achieving a complete dechlorination of the TCE (Barnes et al., 2010a; Bhattacharyya et al., 2010; Zhang et al., 2011; Vijayakumar et al., 2013). The zero-valent iron (nZVI) and bimetallic (for example, palladium-doped) nZVI immobilized in a support and electrospun nanofibrous mats were also applied for TCE degradation without the accumulation of chlorinated intermediates (Kim et al., 2010; Ma et al., 2012). Modified Fe nanoparticles were also tried for improving the TCE degradation. Nanoscale emulsified zero-valen iron (nEZVI) was used for TCE degradation both from soil and ground water (Quinn et al., 2005; Macé et al., 2006; O'Hara et al., 2006; US EPA, 2008; CLU-IN, 2009).

The application of $F_{e}$ nanoparticles creates conditions for abiotic degradation of TCE followed by biological degradation (Henn and Waddill, 2006). A combination of bimetallic nanoparticles and indigenous dechlorinating bacteria, however, requires employing a two-step process. An initial stimulated biodegradation of TCE followed by the addition of bimetallic nanoparticles to degrade the remaining cis-1,2-DCE and VC (Henn and Waddill, 2006; Barnes et al., 2010b). For effective nanoremediation of TCE, however, few site-specific requirements must be met including porosity, hydraulic conductivity, flow velocity, geochemical properties etc. Furthermore, the effect of soil sorption on the effectiveness of bimetallic nanoparticles must be taken into account in process design for the effectiveness of surfactant uses.

Furthermore, a hybrid electrolysis and Pd-catalytic oxidation process was also applied for TCE degradation in groundwater (Yuana et al., 2013) and oxidation was shown to be dominant pathway for degradation instead of hydrodechlorination (Yuan et al., 2012). Titanium nanotubes loaded with Pd-Ti were also used effectively for TCE degradation in groundwater (Xie et al., 2013) and $\mathrm{Pd}-\mathrm{Ti} / \mathrm{TiO}_{2}$ cathode shows superior performance for TCE reduction as compared with other common cathodes. The decreased electrocatalytic activity of the cathode with repeated treatments, however, needs structural improvement.

Finally, a number of comprehensive reviews are reported in literature so far addressing TCE issues and remediation covering many critical aspects. Arp et al. (2001) discussed in detail the molecular and cellular fundamental of TCE aerobic cometabolism. They thoroughly discussed the types of enzymes and their related reactions. Pant and Pant (2010) established a review on microbial remediation of TCE. They presented the discussion on advances in cometabolic reductive dechlorination, co-metabolism, direct oxidation of TCE, Microbiology of TCE degradation and possibilities of bio augmentation. Suttinum and Luepromachai, (2013) thoroughly discussed the concepts, limitations and available strategies for sustained biodegradation of TCE. For abiotic degradation of chlorinated ethanes and ethenes in water, Tobiszewski and Namiesnik, (2013) reviewed the available literature reports. There are some other reviews on topics like phytoremediation of TCE and molecular techniques (Furukawa, 2000a,b; Furukawa et al., 2002; Wood, 2008). However, the degradation efficiency and sustainability of TCE depends directly or indirectly upon the environmental conditions and on the design of engineered system. The objective of this review is to assess the problems related with TCE dynamics in the 
environment and to present a comprehensive review of the engineered systems utilizing the biological degradation ability of microorganisms.

\section{Dynamics and implications of TCE occurrence and removal}

There are two distinct features in TCE (and other similar chlorinated hydrocarbons) pollution scenarios. Firstly, TCE is not only volatile but also possess good adsorption to soil and organic matter and moderate water solubility (Karami et al., 2012). Secondly TCE is generally toxic, persistent and cause bioaccumulation with respect to natural attenuation as compared to many common pollutants (Smidt et al., 2000; Rittmann and McCarty, 2001). On the other hand, TCE contamination level also varies in different media. For example, TCE levels between $0.001 \mu \mathrm{g} \mathrm{I}^{-1}$ to $100 \mu \mathrm{g} \mathrm{I}^{-1}$ have been reported in Canadian surface water while higher levels ranging from under $1000 \mu \mathrm{g} \mathrm{I^{-1 }}$ to almost $10^{6} \mu \mathrm{g} \mathrm{I^{-1 }}$ in the groundwater at various contaminated sites (CEPA, 1993) are reported. High levels (10 to $100000 \mu \mathrm{g} \mathrm{I}^{-1}$ ) have also been reported following a spill in the contaminated sediment of St. Clair River, Canada (CEPA, 1993). In the sediment at $6 \%$ of the 388 US observation stations, TCE has been detected at a median level of $5 \mu \mathrm{g}$ per $\mathrm{kg}$ of dry sediment weight (Staples et al., 1985; ATSDR, 1995). It has been estimated that a typical daily intakes inhalation by the general U.S. population is $13 \mu \mathrm{g}$ day $^{-1}$. United Stated EPA reported an intake of about $5 \mu \mathrm{g}$ day $^{-1}$ via food although it was based on limited data. TCE exposure through air is quickest depending upon whether it is occupation site or open air. In a review by Bakke et al. (2007), occupational exposure to TCE was assessed and the measurements across all industries and decades were $38.2 \mathrm{ppm}$ (arithmetic mean). The level could be the hundreds of ppm $\left(>500,000 \mu \mathrm{g} \mathrm{m}^{-3}\right)$ at short term exposures in industrial sites e.g. aircraft industry. Similar contamination of TCE have been reported in other industrial economies e.g. Japan, Korea, Vietnam, Thailand etc. Hence, if TCE is to low it may not be available for degradation and if it is too high it may be toxic and may cause pollution over huge areas persistently for long time spans.

The "Molecular Recalcitrance" or persistence of organic compounds like TCE in natural systems has been summarized by Alexander (1965) and Rittman and McCarty (2001). They listed following factors:

1. Molecular structure of the pollutant: if the molecular structure of the organic pollutant is not inherently biodegradable biodegradation will not occur because structural characteristic of the pollutant molecule prevents the degradation enzyme from acting.

2. Environmental conditions i.e. either the compound is inaccessible or unavailable, microorganism cannot grow due to some deficiency, the environment is toxic to microbes or the concentration of the pollutant is very high, or once the enzyme produced it is inactivated

3. Appropriate organisms are not present in the environment.

Hence to bring natural attenuation to TCE and similar organic compounds, these factors must be addressed. Many engineered systems have been devised to get complete or enhanced removal/degradation of TCE via physical, biological and chemical unit processes. Selection of the remediation (engineered) process falls in two major but basic targets which are partial degradation/removal from water and soil to air and complete mineralization and control of toxic byproducts during a degradation process of any type.

Initially from any surface/groundwater and sediments etc. evaporation was found to be the primary route of removal of TCE which is merely shifting the TCE from one medium to another without actually destroying it, into simple harmless end products. Physical processes/technologies such as pump-andtreat, air sparging coupling with vapor extraction, in well aeration, soil excavation and venting, (activated carbon) adsorption etc. have been employed in this regard, which have been found relatively slow, costly, and inefficient, along with being environmentally disruptive in nature (Lorah et al., 1997; Bankston, 2002; Han et al., 2002). In addition, many factors affect the efficiency of physical removal processes e.g. the complex nature of aquifers, sorption onto soil media, and entrapment in the porous media (Beeman and Bleckmann, 2002). 
Low efficiency and no treatment of TCE lead the researchers to shift towards more advance and sustainable engineered systems to mineralize TCE to simpler end products. Engineered processes based on sole principle like biological or chemical and hybrid like physical-biological and biological-chemical have been extensively reported to get high efficiency and complete degradations of TCE. In biological or chemical treatment systems of TCE, transport of reactant/substrates to target sites is a crucial step in process efficiency, for example in cometabolism of TCE (Goltz et al., 2001). How efficient the process is, it is only valuable when the required ingredients meet in appropriate concentrations and conditions. It is especially important during in-situ remediation of polluted soils, sediment and aquifers. Even if all the required conditions (listed earlier in this section described by Alexander (1965) and Rittmann and McCarty (2001) are provided, there are still many performance related issues with engineered systems. TCE is highly chlorinated compound and its degradation is not completed in one step, both in biological and chemical processes. Hence before the complete mineralization, it takes number of routes and intermediates. In many cases these intermediates or daughter products are more toxic than TCE itself. Chemical dechlorination or anaerobic dechlorination and chemical reductive dechlorination, for example produces VC in first step (Horber et al., 1999; Middeldorp et al., 1999; Keppler et al., 2002; Zhang and Bennett, 2005; Tobiszewskiand and Namiesnik, 2012; Huang et al., 2013). This following section will present the evaluation of different biological engineered systems for TCE degradation, reported in literature with respect to the control of such performance related parameters.

\section{Biological mineralization of TCE via engineered systems}

There are different approaches of biological degradation of TCE. So far studies on aerobic cometabolism, anaerobic dehalogination, direct oxidation and phytoremediation have been reported using biological processes to degrade TCE. TCE is considered persistent with respect to biological degradation due to its highly chlorinated structure. Microbial degradation of chlorinated compounds depends on chlorine substitution and is highly strain dependent. Specific microbial cultures can utilize most of the monohalogenated compounds. Compounds having more than one halogen atoms (e.g. TCE) are more recalcitrant in nature (Janssen and Witholt, 1992). Biological degradation of TCE through aerobic and anaerobic bacteria is possible and has been reported in lab scale studies and in natural environments. It is stated that TCE can be degraded by enzymatic reaction through a process termed as cometabolism. Cometabolism is "the fortuitous transformation of a compound by enzymes or co-factors designed for other purposes" (Rittmann and McCarty, 2001). In TCE aerobic cometabolism, nonspecific enzymes (e.g. methane mono-oxygenase, toluene mono-oxygenase, and toluene di-oxygenase) forms an epoxide that is chemically unstable and degrades to simpler end products. There are three crucial ingredients for initiation and completion of cometabolism that is microorganism that can produce non-specific enzyme, a co-substrate that can induces the non-specific (e.g. methane, toluene, ammonia) and oxygen (Rittman and McCarty, 2001). Proper working environment and conditions are also required for the cometabolism.

Toxicity of TCE (and its cometabolic byproducts) to microorganism, viability of microorganisms, competition for enzymes and substrates, inactivation of enzymes, slower kinetics as compared to normal metabolism, low utilization for substrate are few of the many factors that affect TCE cometabolic mineralization (Arp et al., 2001). Many engineered systems have been reported in literature to address these issues and to get the complete, sustained and highly efficient TCE degradation through biological cometabolism. Following section will review the literature for different engineered systems.

Aerobic cometabolism for TCE degradation was evaluated by Wilson and Wilson (1985), Little et al. (1985), and Alvarez-Cohen and McCarty (1991) on early stages using methane Mono-oxygenase (MMO). Soon it was clear that there are substrates and microorganism other than methane oxidizing bacteria that can also help to express non-specific enzymes. Soluble methane monooxygenase, Toluene 2monooxygenase, Toluene dioxygenase,Soluble butane monooxygenase,Isopropylbenzenedioxygenase, Isopropyl benzene/toluene dioxygenase, Alkene monooxygenase,Butane monooxygenase,Butane monooxygenaseare the examples of enzymes that can cause TCE cometabolism (Oldenhuis et al., 1989; 
Wackett and Householder, 1989; Fox et al., 1990; Dabrock et al., 1992, 1994; Landa et al., 1994; Hyman et al., 1995; Chu and Alvarez-Cohen, 1996; 1998; 1999; Pflugmacher et al., 1996; Newman and Wackett, 1997; Lange and Wackett, 1997; Saeki et al., 1999; Yang et al., 1999; Milintawisamai et al., 2001; Yeager et al., 2001;2004; Morono et al., 2004, 2006; Suttinun et al., 2004; Halsey et al., 2005; Kocamemi and Cecen, 2007, 2010; Suttinun et al., 2010).

Phelps et al. (1990) used expanded bed bioreactors to degrade TCE in continuous cycles using mixed bacterial cultures that utilized methane, propane, and tryptone-yeast extract as aerobic carbon and energy sources. They achieved 95\% TCE removal in 5 days. However the pH shift from 7 to 7.5 decreased the efficiency by $85 \%$. Landa et al. (1994) used Burkholderia cepacia G4 to degrade TCE in a chemostate using toluene as energy and growth substrate. It was found that increasing the loading of TCE, effects the efficiency of TCE conversion. However, specific TCE degradation activity of the cells and the volumetric activity increased. TCE loading as high as $3,400 \mu \mathrm{mol}$ per liter per $\mathrm{h}$ for $12 \mathrm{~h}$ caused inhibition of toluene and TCE conversion, which recovered to within two days after reduction of the TCE load to the original nontoxic level. In a study by Uchiyama et al. (1994), immobilization of Methylocystis sp. Strain $M$ in Different Matrices resulted in different results. Cells immobilized in Ca-alginate, zcarrageenan, and agarose showed higher or almost the same degradation activity in comparison with that of free cells, while low activity was observed in the cells immobilized in photocross linkable resin, polyurethane, and polyelectrolyte complex. The optimum pH and temperature was found to be 7 and 35 degrees Celsius, respectively. Shimomura et al. (1997) developed a fluidized-bed bioreactor (FBB) containing Methylocystis sp. strain M (strain $M$ ) immobilized in $2 \%$ calcium alginate gel beads for treating synthetic groundwater containing TCE which was supplied with a methane/air gas mixture. About $80-90 \%$ of the influent TCE was degraded in the reactor. However, the efficiency of the gelimmobilized cells to degrade TCE declined rapidly during the TCE degradation process. They operated the reactor on alternate days for TCE degradation and reactivation of the immobilized strain $M$. Sun and Wood (1996) developed a fixed film, aerobic, single-pass, bioreactor for the continuous degradation and mineralization of gas-phase TCE using Burkholderia cepacia PR123 (TOM23C) which was immobilized on sintered glass and activated carbon. Repeated starving of the cells was found to restore TOM activity in the bioreactor with activated carbon and extended TCE mineralization by $34 \%$. Smith and McCarty (1997) evaluated a two-stage (first mixed culture growth and secondly, a plug flow TCE degrading reactor. When methane was added to the TCE degrading reactor, it inhibited TCE cometabolism at low TCE concentrations and enhanced TCE cometabolism at high TCE concentrations. The results indicated that the TCE cometabolism in the presence of methane does not follow simple competitive inhibition kinetics. Radway et al. (1998) used polyurethane foam embedded Burkholderia cepacia G4 to degrade TCE using benzene as growth substrate. They found that foam embedded Burkholderia cepacia G4 degradation efficiency enhanced but there was adsorption of TCE onto polyurethane foam which may not be available for degradation. It was also noticed that TCE and benzene also increased the binding of the foam.

Sipkema et al. (1999) evaluated TCE degradation in a two stage system by Methylosinus trichosporium $\mathrm{OB} 3 \mathrm{~b}$ using formate and methane. In first stage the organism Methylosinus trichosporium OB3b was grown; in the second reactor, the cells degraded TCE. They described that the system presented is flexible (oxygen/methane addition) and can easily be scaled up for field application with $90 \%$ reduction in operating cost of chemicals. Nakano et al. (2000) studied the effect of TCE adsorption on granular activated carbon (GAC) and possibility of biological degradation and to determine the adsorption capacity of bio-regenerated GAC. $82.5 \%$ of the total TCE $(26.2 \mathrm{mg})$ adsorbed in the GAC was degraded successfully. They concluded that the adsorption capacity of the bio regenerated GAC was very low and was not feasible to be recycled for TCE adsorption without thermal regeneration.

Dolasa and Ergas (2000) used a hollow fiber membrane bioreactor to investigate the degradation of TCE by mixed culture using toluene as growth substrate. The membrane bioreactor consisted of a bundle of polypropylene fibers and air containing volatile organic compounds was subjected to pass through theses fibers. Batch culture experiments showed that no inhibition to the toluene degrading ability was observed at up to $15 \mathrm{mg}$ per L toluene or up to $1.5 \mathrm{mg}$ per L TCE and about $80 \%$ TCE degradation was 
observed. Brar and Gupta (2000) used rotating biological contactor (RBC) at laboratory scale to treat synthetic wastewater containing $30 \mathrm{mg} \mathrm{I}^{-1}$ of TCE. They used mixed culture consisting of nitrifiers, heterotrophs and Thiosphaera pantotropha to achieve 99.89\% removal of TCE under loading of $0.0039 \mathrm{~m}^{3} \mathrm{~m}^{-2} \mathrm{~d}^{-1}$ and HRT 3.5 days. Guo et al. (2001) developed a fibrous bed reactor todegrade TCE by Pseudomonas putida F1 (P. putida F1) using toluene. They reported that competitive inhibition of toluene on TCE removal could be prevented in this bioreactor. 90\% TCE was removed over $4 \mathrm{~h}$ when 95 mg toluene $\mathrm{I}^{-1}$ was presented simu'taneously. Lee et al. (2003) developed a trickling biofilter system for continuous treatment of gas-phase trichloroethylene. The system consisted on two units. Unlike to the previous studies, they used first unit to degrade TCE and the second for the reactivation of inactive biofilm. Gas phase TCE was degraded continuously by Burkholderia cepacia G4 achieving a $100 \%$ removal of TCE with a maximum TCE elimination capacity of $17 \mathrm{mg}$ per $\mathrm{L}$ per day. Dursun and Tepe (2005) used Ca-alginate immobilized Ralstonia eutropha to degrdade TCE using phenol as substrate. They found that Phenol had a strong inhibitory effect and the results showed that intra-particle diffusion resistance was important for this system. Tartakovsky et al. (2005) used coupled anaerobic-aerobic granular biofilm reactor to degrade TCE. The experiment showed the degradation of TCE due to the COexistence of methanogenic and methanotrophic populations in a single reactor. Chen et al. (2007) encapsulated P. putida F1 strain into chitosan beads and successfully degraded TCE using phenol as cosubstrate. They found that TCE degradation kinetics were government by diffusion kinetics. Kim et al. (2010) degraded TCE via polyethylene glycolpolymer encapsulation of P. putida and Bacillus Sp strain via toluene metabolism. The degradation by Bacillus $\mathrm{Sp}$ was reported first time and the specific transformation efficiency of TCE was found higher than the other species reported in the literature. Kumar et al. (2012) used Burkholderia vietnamiensis G4 (the pure cultures of naturally-occurring bacteria are) in engineered systems in the biodegradation of TCE. Hamed et al. (2013) used P. putida F1 (strain ATCC 700007) at different concentrations in both single- and two-phase systems using 2undecanone as the second organic phase. Two-phase system not only prevented the inhibition effect of high concentrations of TCE on the microbial biomass but also decreased the biodegradation time of TCE.

\section{Future work and conclusions}

TCE is found in all mediums of environment including soil, air and water. Although at some polluted sites natural attenuation of TCE has been found to occur but generally the natural process is very slow. Biological engineered systems have been found to degrade TCE on much faster rates and higher concentrations. Different combination of materials, microorganism and reactor setup have been presented in this study which emphases on the importance of various inter disciplinary (e.g. physicobiological, chemical-biological) approaches to get sustainable and highly efficient TCE detoxification and degradation processes. The composite nanofibrous mats having high surface area to volume ratio and porosity and immobilized with the bimetallic nanoparticles are the promising future applications in remediation of various environmental contaminants like TCE.

The question emerges, however, as to what kind of engineered systems would be most useful for maximizing the degradation of TCE in a sustainable way and where it might be implemented. Cometabolism may not be a sustainable TCE degradation approach and so as the reductive dechlorination unless an electron donor is provided. After reviewing the literature, it can be concluded that cometabolic degradation of TCE at low concentrations may not be an issue but its biological treatment is limited by the intrinsic properties of different methods and bacteria due to their toxicity. It is recommended to add to the aqueous medium a second distinct organic phase for degrading fast and high concentration of TCE. By using biocatalysts containing water-immiscible organic solvents, it is possible to degrade high concentrations of TCE at fast rates especially when it is known that TCE is toxic for the microorganisms. These catalysts will help maintain a low concentration of TCE in the aqueous phase even though the overall concentration remains high. This second phase (i.e. organic) can be reused again since it does not mix with the aqueous phase which can be easily separated and discharged. 
Currently, there is a pressing need to identify the appropriate microorganisms in any engineered system that can effectively provide a low-cost treatment option for TCE degradation. Indigenous populations of bacteria may be stimulated by various sources of nutrients that selectively enhance the biodegrading bacteria present in any engineered system. Analytical chemistry can reveal what nutrients might be limiting for biodegradation to occur at a maximal rate. It is equally important to point the way toward identification and characterization of the most suitable bacteria that thrive in the presence of available nutrients. The best microorganism for TCE degradation should have high TCE-degrading enzyme activity, high transformation capacity for TCE, and grow relatively rapidly. The effect of the substrate concentration and the cell concentration on the biodegradation of TCE should be investigated carefully to degrade its high concentrations at fast rates. The second phase (i.e. organic) should be selected in an appropriate way considering its insolubility, volatility, non-biodegradability by the selected microorganism and the cost of the overall engineered system. In conclusion, we feel that biodegradation offers the potential of cost effective treatment of TCE. It is necessary, however, that engineered systems effectively use the biodegradative metabolism that nature has evolved.

\section{Acknowledgments}

"The authors would like to extend their sincere appreciation to the Deanship of Scientific Research at King Saud University for its funding of this research through the Research Group Project no. RGP-VPP-283."

\section{References}

Agency for Toxic Substances and Disease and Registry (ATSDR) (2009), Toxicological profile for trichloroethylene, Department of Health and Human Services. Atlanta, U.S.A.

Al-Abed S.R. and Fang Y.X. (2007), Use of granular graphite for electrolytic dechlorination of trichloroethylene, Environmental Engineering Science, 24, 842-851.

Alexander M. (1965), Biodegradation: problems of molecular recalcitrance and microbial fallibility, Advances in Applied Microbiology, 7, 35-80.

Alvarez-Cohen L. and McCarty P.L. (1991), Effects of toxicity, aeration, and reductant supply on trichloroethylene transformation by a mixed methanotrophic culture, Applied and Environmental Microbiology, 57, 228-235.

Arp D.J., Yeager C.M. and Hyman M.R. (2001), Molecular and cellular fundamentals of aerobic cometabolism of trichloroethylene, Biodegradation, 12, 81-103.

Bakke B., Stewart P.A. and Waters M.A. (2007), Uses of and exposure to trichloroethylene in U.S. industry: a systematic literature review, Journal of Occupation and Environmental Hygiene, 4, 375-90.

Bankston J.L., Sola D.L., Komor A.T. and Dwyer D.F. (2002), Degradation of trichloroethylene in wetland microcosms containing broad-leaved cattail and eastern cottonwood, Water Research, 36, 1539-1546.

Barnes R.J., Riba O., Gardner M.N., Scott T.B., Jackman S.A. and Thompson I.P. (2010a), Optimization of nano-scale nickel/iron particles for the reduction of high concentration chlorinated aliphatic hydrocarbon solutions, Chemosphere, 79(4), 448-454.

Barnes R.J., Riba O., Gardner M.N., Singer A.C., Jackman S.A. and Thompson I.P. (2010b), Inhibition of biological TCE and sulphate reduction in the presence of iron nanoparticles, Chemosphere, 80(5), 554-562.

Beeman R.E. and Bleckmann C.A. (2002), Sequential anaerobic aerobic treatment of an aquifer contaminated by halogenated organics: Field results, Journal of Contamination Hydrology, 57, 147-159.

Bhattacharyya D., Xu J., Smuleac V., Lewis S., Ormsbee L. and Bachas L. (2010), Nanotechnology for TCE and PCB Dechlorination from Water: Nanoparticle Synthesis and Reactivity, World Environmental and Water Resources Congress, 411-416.

Brar S.K. and Gupta S.K. (2000), Biodegradation of trichloroethylene in a rotating biological contactor, Water Research, 34, 4207-4214.

Canadian Environmental Protection Act (CEPA), (1993), Priority substances list assessment report: trichloroethylene, Environment Canada, Health Canada. 
Carter K.E. and Farrell J. (2009), Electrochemical oxidation of trichloroethylene using boron-doped diamond film electrodes, Environmental Science \& Technology, 43, 8350-8354.

Chen Y., Lin T., Huang C., Lin J. and Hsieh F. (2007), Degradation of phenol and TCE using suspended and chitosan bead immobilized Pseudomonas Putida, Journal of Hazardous Materials, 148, 660-670.

Chiao F.F., Currie R.C. and McKone T.E. (1994), Intermedia transfer factors for contaminants found at hazardous waste sites: Trichloroethylene (TCE), A Research Report of Department of Environmental Toxicology, University of California, USA.

Chiu W.A., Jinot J., Scott C.S., Makris S.L., Cooper G.S., Dzubow R.C., Bale A.S., Evans M.V., Guyton K.Z., Keshava K., Lipscomb J.C., Barone Jr. B., Fox J.F., Gwinn M.R., Schaum J. and Caldwell J.C. (2013), Human Health Effects of Trichloroethylene: Key Findings and Scientific Issues, Environ Health Perspective, 121, 303-311.

Chu K.H. and Alvarez-Cohen L. (1996), Trichloroethylene degradation by methane-oxidizing cultures grown with various nitrogen sources, Water and Environmental Research, 68, 76-82.

Chu K.H. and Alvarez-Cohen L. (1998), Effect of nitrogen source on growth and trichloroethylene degradation by methaneoxidizing bacteria, Applied and Environmental Microbiology, 64, 3451-3457.

Chu K.H. and Alvarez-Cohen L. (1999), Evaluation of toxic effects of aeration and trichloroethylene oxidation on methanotrophic bacteria grown with different nitrogen sources, Applied and Environmental Microbiology, 65, 766-772.

CLU-IN. (2009), CLU-IN technology focus - Nanotechnology use in environmental remediation website draft, (http://clu-in.org/).

Cope D.B. and Benson C.H. (2009), Grey-iron foundry slags as reactive media for removing trichloroethylene from groundwater, Environmental Science \& Technology, 43, 169-175.

Dabrock B., Kebeler M., Averhoff B. and Gottschaalk G. (1994), Identification and characterization of a transmissible linear plasmid from Rhodococcus erythropolis BD2 that encodes isopropylbenzene and trichloroethylene catabolism, Applied and Environmental Microbiology, 60, 853-860.

Dabrock B., Riedel J., Bertram J. and Gottschalk G. (1992), Isopropylbenzene (cumene): a new substrate for the isolation of trichloroethene-degrading bacteria, Arch Microbiology, 158, 9-13.

Dolasa A.R. and Ergas S.J. (2000), Membrane bioreactor for cometabolism of trichloroethylene air emissions, Journal of Environmental Engineering, 126, 969-973.

Dong Y.R., Liang X.M., Krumholz L.R., Philp R.P. and Butler E.C. (2009), The relative contributions of abiotic and microbial process to the transformation of tetrachloroethylene and trichloroethyelene in anaerobic microcosms, Environmental Science \& Technology, 43, 690-697.

Dursun A.Y. and Tepe O. (2005), Internal mass transfer effect on biodegradation of phenol by Ca-alginate immobilized Ralstonia eutropha, Journal of Hazardous Materials, 126, 105-111.

Fox B.G., Borneman J.G., Wackett L.P. and Lipscomb J.D. (1990), Haloalkene oxidation by the soluble methane monooxygenase from Methylosinus trichosporium OB3b: mechanistic and environmental applications, Biochemistry, 29, 6419-6427.

Furukawa K. (2000a), Engineering dioxygenaes for efficient degradation of environmental pollutants, Current Opinion in Biotechnology, 11, 244-249

Furukawa K. (2000b), Biochemical and genetic bases of microbial degradation of polychlorinated biphenyls (PCBs), Journal of General and Applied Microbiology, 46, 283-296.

Furukawa Y., Kim J.W., Watkins J. and Wilkin R.T. (2002), Formation of ferrihydrite and associated iron corrosion products in permeable reactive barriers of zero-valent iron, Environmental Science \& Technology, 36, 5469-5475.

Goltz M., Bouwer E. and Huang J. (2001), Transport issues and bioremediation modeling for the in-situ aerobic cometabolism of chlorinated solvents, Biodegradation, 12, 127-140.

Guo G.L., Tseng D.W. and Huang S.L. (2001), Co-metabolic degradation of trichloroethylene by Pseudomonas putida in a fibrous bed bioreactor, Biotechnology Letters, 23, 1653-1657.

Halsey K.H., Sayavedra-Soto L.A., Bottomley P.J. and Arp D.J. (2005), Trichloroethylene degradation by butaneoxidizing bacteria causes a spectrum of toxic effects, Applied Microbiology and Biotechnology, 68, 794-801 
Hamed T.A., Bayraktar E., Mehmetoglu T. and Mehmetoglu U. (2013), Cometabolic Degradation of Trichloroethylene by Single- and Two-Phase Systems, Soil and Sediment Contamination, 22(1), 85-94.

Han T.S., Sasaki S., Yano K., Ikebukuro K., Kitayama A. and Nagamune T. (2002), Flow injection microbial trichloroethylene sensor, Talanta, 57, 271-276.

Henn K.W. and Waddill D.W. (2006), Utilization of nanoscale zero-valent iron for source remediation-a case study, Remediation, 16(2), 57-77.

Horber C., Christensen N. and Arvin E. (1999), Tetrachloroethene dechlorination kinetics by Dehalospirillum multivorans immobilized in up flow anaerobic sludge blanket reactors, Applied Microbiology and Biotechnology, 51, 694-699.

Huang W., Liu F., Yan N., Lu A., Chen H., Chen L. and Wang F. (2013), Removal of trichloroethylene in groundwater with two oxidants: siderite catalyzed hydrogen peroxide and sodium persulfate, Water Science \& Technology: Water Supply, 13, 36-43

Hyman R.D., Russell A.S., Ely L.R., Williamson J.K. and Arp D.J. (1995), Inhibition, inactivation and recovery of ammonia-oxidizing activity in co-metabolism of trichloroethylene by Nitrosomonas europaea, Applied and Environmental Microbiology, 61, 1480-1487.

Jacoby W.A., Blake D.M. and Watt A.S. (1998), Remediation of trichloroethylene or perchloroethylene contamination, In: Meyers, R. A. (eds.), Encyclopedia Weries in Environmental sciences: Environmental Analysis \& Remediation, Wiley Blackwell, USA, p. 4847-4873.

Janssen D.B. and Witholt B. (1992), Aerobic and Anaerobic degradation of halogenated aliphatics. In: Sigel, H. and Sigel, A. (eds.), Metal lons in Biological Systems, Vol. 28. New York, Marcel Dekker, 299-327.

Karami S., Lan Q., Rothman N., Stewart P.A., Lee L.M., Vermeulen R. and Moore L.E. (2012), Occupational trichloroethylene exposure and kidney cancer risk: a meta-analysis, Occupational and Environmental Medicine, 69, 858-867.

Karn B., Kuiken T. and Otto M. (2009), Nanotechnology and in Situ Remediation: A Review of the Benefits and Potential Risks, Environmental Health Perspectives, 117, 1823-1831.

Katsanou O., Zervas E., Poulopoulos S.G. and Philippopoulos C. J. (2008), Photocatalytic oxidation of TCE and MTBE in the Gas phase, Global NEST Journal, 10(2), 237-240.

Keppler F., Borchers R., Pracht J., Rheinberger S. and Scholer H.F. (2002), Natural formation of vinyl chloride in the terrestrial environment, Environmental Science \& Technology, 36, 2479-2483.

Kim H., Hong H.J., Jung J., Kim S.H. and Yang J.W. (2010), Degradation of trichloroethylene (TCE) by nanoscale zerovalent iron (nZVI) immobilized in alginate bead, Journal of Hazardous Materials, 176(1-3),1038-1043.

Kim S., Bae W., Hwang J. and Park J. (2010), Aerobic TCE degradation by encapsulated toluene-oxidizing bacteria, Pseudomonas putida and Bacillus spp, Water Science and Technology, 62, 1991-1997.

Kocamemi B.A. and Cecen F. (2007), Kinetic analysis of the inhibitory effect of trichloroethylene (TCE) on nitrification in cometabolic degradation, Biodegradation, 18, 71-81.

Kocamemi B.A. and Cecen F. (2010), Biological removal of the xenobiotic trichloroethylene (TCE) through cometabolism in nitrifying systems, Bioresource Technology, 101, 430-433.

Kumar A., Vercruyssen A., Dewulf J., Lens P. and Van Langenhove H. (2012), Removal of gaseous trichloroethylene (TCE) in a composite membrane biofilm reactor, Journal of Environmental Science and Health Part AToxic/Hazardous Substances \& Environmental Engineering, 47, 1046-1052.

Landa A.S., Sipkema E.M., Weijma J., Beenackers A.A., Dolfing J. and Janssen D.B. (1994), Cometabolic degradation of trichloroethylene by Pseudomonas cepacia G4 in a chemostat with toluene as the primary substrate, Applied and Environmental Microbiology, 60, 3368-337.

Lange C.C. and Wackett L.P. (1997), Oxidation of aliphatic olefins by toluene dioxygenase: enzyme rates and product identification, Journal of Bacteriology, 179, 3858-3865.

Lee E.Y., Ye B.D. and Park S.H. (2003), Development and operation of a trickling bio filter system for continuous treatment of gas-phase trichloroethylene, Biotechnology Letters, 25, 1757-1761.

Little C.D., Palumbo A.V., Herbers S.E., Lidstrom M.E., Tyndall R.L. and Gilmer P.J. (1988), Trichloroethylene Biodegradation by a Methane-Oxidizing Bacterium, Applied and Environmental Microbiology, 54, 951-956. 
Lohner S.T., Becker D., Mangold K.M. and Tiehm A. (2011), Sequential reductive and oxidative biodegradation of chloroethenes stimulated in a coupled bio-electro-process, Environmental Science \& Technology, 45, 64916497.

Lorah M.M., Olsen L.D., Smith B.L., Johnson M.A. and Fleck W.B. (1997), Natural attenuation of chlorinated volatile organic compounds in a Freshwater Tidal Wetland, Aberdeen Proving Ground, Maryland, In: Water Resource Investigation Report No. 97-4171 of US Geological Survey. USA.

Ma H., Huang Y., Shen M., Guo R., Cao X. and Shi X. (2012), Enhanced dechlorination of trichloroethylene using electrospun polymer nanofibrous mats immobilized with iron/palladium bimetallic nanoparticles, Journal of Hazardous Materials, 211-212: 349-356.

Macé C., Desrocher S., Gheorghiu F., Kane A., Pupeza M., Cernik M., Kvapil P., Venkatakrishnan R. and Zhang W-X. (2006), Nanotechnology and groundwater remediation: a step forward in technology understanding, Remediation, 16(2), 23-33.

Mao X.H., Ciblak A., Amiri M. and Alshawabkeh A.N. (2011), Redox control for electrochemical dechlorination of trichloroethylene in bicarbonate aqueous media, Environmental Science \& Technology, 46, 3398-3405.

Mao X.H., Ciblak A., Baek K., Amiri M., Loch-Caruso R. and Alshawabkeh A.N. (2012), Optimization of electrochemical dechlorination of trichloroethyelene in reducing electrolytes, Water Research, 46, 18471857.

Middeldorp P.J.M., Luijten M.L.G.C. and van de Pas B.A. (1999), Anaerobic microbial reductive dehalogenation of chlorinatedethenes, Bioremediation Journal, 3, 151-169.

Milintawisamai M., Chanarong S., Sunthondecha P., Savesthayothin V. and Pantachak C. (2001), Contamination of chlorinated ethylene in soil and groundwater: the case study of Thailand (in Thai). Research development and technology promotion group, the environmental research and training center, Department of Environmental Quality Promotion, Bangkok.

Mishra D., Liao Z.H. and Farrell J. (2008), Understanding reductive dechlorination of trichloroethene on borondoped diamond film electrodes, Environmental Science \& Technology, 42, 9344-9349.

Morono Y., Unno H. and Hori K. (2006), Correlation of TCE cometabolism with growth characteristics on aromatic substrates in toluene-degrading bacteria, Biochemical Engineering Journal, 31, 173-179.

Morono Y., Unno H., Tanji Y. and Hori K. (2004), Addition of aromatic substrates restores trichloroethylene degradation activity in Pseudomonas putida F1, Applied and Environmental Microbiology, 70, 2830-2835

Nakano Y., Hua L.Q. Nishijimam W., Shoto E. and Okada M. (2000), Biodegradation of Trichloroethylene (TCE) adsorbed on granular activated carbon (GAC), Water Research, 34, 4139-4142.

Newman L.M. and Wackett L.P. (1997), Trichloroethylene oxidation by purified toluene 2-monooxygenase: products, kinetics, and turnover-dependent inactivation, Journal of Bacteriology, 179, 90-96.

O'Hara S., Krug T., Quinn J., Clausen C. and Geiger C. (2006), Field and laboratory evaluation of the treatment of DNAPL source zones using emulsified zero-valent iron, Remediation, 16(2), 35-56.

Oldenhuis R., Vink R.L.J.M., Janssen D.B. and Witholt B. (1989), Degradation of chlorinated aliphatic hydrocarbons by Methylosinustrichosporium OB3b expressing Soluble Methane Monooxygenase, Applied and Environmental Microbiology, 55, 2819-2826.

Pant P. and Pant S. (2010), A review: advances in microbial remediation of trichloroethylene (TCE), Journal of Environmental Sciences, 22, 116-126.

Petersen M.A., Sale T.C. and Reardon K.F. (2007), Electrolytic trichloroethene degradation using mixed metal oxide coated titanium mesh electrodes, Chemosphere, 67, 1573-1581.

Pflugmacher U., Averhoff B. and Gottschalk G. (1996), Cloning, sequencing, and expression of isopropylbenzene degradation genes from Pseudomonas sp. Strain JR1: identification of isopropylbenzenedioxygenase that mediates trichloroethene oxidation, Applied and Environmental Microbiology, 62, 3967-3977.

Phelps T.J., Niedzielski J.J, Schram R.M, Herbers S.E. and White D.C. (1990), Biodegradation of trichloroethylene in continuous-recycle expanded-bed bioreactors, Applied and Environmental Microbiology, 56, 1702-1709.

Phillips D.H., Van Nooten T., Bastiaens L., Russell M.I., Dickson K., Plant S., Ahad J.M.E., Newton T., Elliot T. and Kalin R.M. (2010), Ten year performance evaluation of a field scale zero-valent iron permeable reactive barrier installed to remediate trichloroethene contaminated groundwater, Environmental Science \& Technology, 44, 3861-3869. 
Quinn J., Geiger C., Clausen C., Brooks K., Coon C., O`hara S., Krug T., Major D., Yoon W.S., Gavaskar A. and Holdswoth T. (2005), Field demonstration of DNAPL dehalogenation using emulsified zero-valent iron, Environmental Science \& Technology, 39, 1309-1318.

Radway J.C., Domingo J.W.S., Hazen T.C. and Wild E.W. (1998), Evaluation of biodegradation potential of foam embedded Burkholderia Cepacia G4, Biotechnology Letters, 20, 663-666.

Rittman B.E. and McCarty P.L. (2001), Detoxification of hazardous chemicals, In: Rittmann, B. E., Perry, L. and McCarty, P. L. (eds.), Environmental Biotechnology: Principles and Applications, New York, McGraw-Hill, 637694.

Russel H.H., Matthews J.E. and Sewell G.W. (1992), Grounwater Issue: TCE removal from contaminated soil and groundwater, In: Research Report No. EPA/540/S-92/002 of USEPA, Washington DC, USA.

Saeki H., Akira M., Furuhashi K., Averhoff B. and Gottschalk G. (1999), Degradation of trichloroethene by a linearplasmid encoded alkene monooxygenase in Rhodococcus corallines (Nocardiacorallina) B-276, Microbiology, 145, 1721-1730

Schettler T., Solomon G., Valenti M. and Huddle A. (1999), Generations at Risk: Reproductive Health and the Environment, MIT Press, Cambridge, 1-397.

Scott C.S. and Jinot J. (2011), Trichloroethylene and Cancer: Systematic and Quantitative Review of Epidemiologic Evidence for Identifying Hazards, International Journal of Environmental Research and Public Health, 8, 4238-4272.

Shimomura T., Suda F., Uchiyama H. and Yagi O. (1997), Biodegradation of trichloroethylene by Methylocystis sp. strain $\mathrm{M}$ immobilized in gel beads in a fluidized-bed bioreactor, Water Research, 31, 2383-2386.

Sipkema E.M., de Koning W., Van Hylckama Vlieg J.E.T., Ganzeveld K.J., Janssen D.B. and Beenackers A.A.C.M. (1999), Trichloroethylene degradation in a two-step system by Methylosinus trichosporium OB3b. Optimization of system performance: use of formate and methane, Biotechnology and Bioengineering, 63, 56-67.

Smidt H. (2000), Halorespiring bacteria - molecular characterization and detection, Enzyme and Microbial Technology, 27, 812-820.

Smith L.H. and McCarty P.L. (1997), Laboratory evaluation of a two stage treatment system for TCE co-metabolism by methane oxidizing mixed culture, Biotechnology and Bioengineering, 55, 650-659.

Staples C.A., Werner A.F. and Hoogheem T.J. (1985), Assessment of priority pollutant concentrations in the United States using STORET database, Environmental Toxicology and Chemistry, 4, 131-142.

Sun A.K. and Wood T.K. (1996), Trichloroethylene degradation and mineralization by pseudomonads and Methylosinus trichosporium OB3b, Applied Microbiology Biotechnology, 45, 248-256.

Suttinum O. and Luepromachai E. (2013), Cometabolism of trichloroethylene: concepts, limitations and available strategies for sustained biodegradation, Reviews in Environmental Science and Biotechnology, 12, 99-114.

Suttinun O., Lederman P.B. and Luepromchai E. (2004), Application of terpene-induced cell for enhancing biodegradation of TCE contaminated soil, Songklanakarin Journal of Science and Technology, 26, 131-142.

Suttinun O., Muller R. and Luepromchai E. (2010), Cometabolic degradation of trichloroethylene by Rhodococcus sp. Strain L4 immobilized on plant materials rich in essential oils, Applied and Environmental Microbiology, 76, 4684-4690.

Tartakovsky B., Manuel M.F. and Guiot S.R. (2003), Trichloroethylene degradation in a coupled anaerobic/aerobic reactor oxygenated using hydrogen peroxide, Environmental Science \& Technology, 37, 5823-5828.

Tobiszewski M. and Namiesnik J. (2012), Abiotic degradation of chlorinated ethanes and ethenes in water, Environmental Science and Pollution Research International, 19(6), 1994-2006.

Tsai T.T., Kao C.M., Yeh T.Y., Liang S.H. and Chien H.Y. (2009), Application of surfactant enhanced permanganate oxidation and biodegradation of trichloroethylene in groundwater, Journal of Hazardous Materials, 161, 111119.

U.S. Environmental Protection Agency. (2008), Office of Solid Waste and Emergency Response. Nanotechnology for Site Remediation Fact Sheet. Report number: EPA 542-F-08-009 (http://www.epa.gov/tio/download/remed/542-f-08-009.pdf) 
U.S. Environmental Protection Agency. (2011), Toxicological review of Trichloroethylene (CASRN 79-01-6) in support of summary information on the Integrated Risk Information System (IRIS). (EPA/635/R-09/011F), Washington, DC.

Uchiyama H., Yagi O., Oguri K. and Kokufuta E. (1994), Immobilization of Trichloroethylene-Degrading Bacterium, Methylocystis sp. Strain M in Different Matrices, Journal of Fermentation and Bioengineering (Now known as Journal of Bioscience and Bioengineering), 77, 73-177.

Vijayakumar N.S., Flower N. A. L., Brabu B., Gopalakrishnan C. and Raja, S.V.K. (2013), Degradation of DCE and TCE by $\mathrm{Fe}-\mathrm{Ni}$ nanoparticles immobilised polysulphone matrix, Journal of Experimental Nanoscience, 8(7-8), 890-900.

Wackett L.P. and Housholder S.R. (1989), Toxicity of trichloroethylene to Pseudomonas putida F1 is mediated by toluene dioxygenase, Applied and Environmental Microbiology, 55, 2723-2725.

Waldemer R.H., Tratnyek P.G., Johnson R.L. and Nurmi J.T. (2007), Oxidation of chlorinated ethenes by heatactivated persulfate: kinetics and products, Environmental Science \& Technology, 41, 1010-1015.

Wilson J.T. and Wilson B.H. (1985), Biotransformation of trichloroethylene in soil, Applied and Environmental Microbiology, 29, 242-243.

Wood T.K. (2008), Molecular approaches in bioremediation, Current Opinion in Biotechnology, 19, 572-578.

Xie W., Yuana S., Mao X., Hua W., Liao P., Tong M. and Alshawabkeh A.N. (2013), Electrocatalytic activity of Pdloaded $\mathrm{Ti} / \mathrm{TiO}_{2}$ nanotubes cathode for TCE reduction in groundwater, Water Research, 47, 3573-3582.

Yang L., Chang Y.F. and Chou M.S. (1999), Feasibility of bioremediation of trichloroethylene contaminated sites by nitrifying bacteria through cometabolism with ammonia, Journal of Hazardous Materials, 69, 111-126.

Yeager C.M., Arthur K.M., Bottomley P.J. and Arp D.J. (2004), Trichloroethylene degradation by toluene-oxidizing bacteria grown on non-aromatic substrate, Biodegradation, 15, 19-28.

Yeager C.M., Bottomley P.J. and Arp D.J. (2001), Cytotoxicity associated with trichloroethylene oxidation in Burkholderia cepacia G4, Applied and Environmental Microbiology, 67, 2107-2115.

Yuan S., Mao X. and Alshawabkeh A.N. (2012), Efficient degradation of TCE in groundwater using Pd and electrogenerated $\mathrm{H}_{2}$ and $\mathrm{O}_{2}$ : a shift in pathway from hydrodechlorination to oxidation in the presence of ferrous ions, Environmental Science \& Technology, 46(6), 3398-3405.

Yuana S., Chen M., Mao X. and Alshawabkeh A.N. (2013), A three-electrode column for Pd-catalytic oxidation of TCE in groundwater with automatic $\mathrm{pH}$-regulation and resistance to reduced sulfur compound foiling, Water Research, 47, 269-278.

Zhang C. and Bennett G.N. (2005), Biodegradation of xenobiotics by anaerobic bacteria, Applied Microbiology and Biotechnology, 67, 600-618.

Zhang M., He F., Zhao D. and Hao X. (2011), Degradation of soil-sorbed trichloroethylene by stabilized zero valent iron nanoparticles: effects of sorption, surfactants, and natural organic matter, Water Research, 45(7), 2401-2414.

Zhang W-X. (2003), Nanoscale iron particles for environmental remediation: an overview, Journal of Nanoparticle Research, 5,323-332.

Zhang W-X. and Elliott D.W. (2006), Applications of iron nanoparticles for groundwater remediation, Remediation, 16(2),7-21. 